UDC 316.77

LBC 60.56

\title{
«LET'S MEET IN AUGMENTED REALITY...»: SOCIAL COMPETENCES OF MMORPG-GAMERS ${ }^{1}$
}

\author{
Olga V. Sergeeva \\ Saint Petersburg State University, Saint Petersburg, Russian Federation
}

Anna V. Tsareva

Saint Petersburg State University, Saint Petersburg, Russian Federation

Nadezhda A. Zinovyeva

Sociological Institute of RAS, Saint Petersburg, Russian Federation

\begin{abstract}
The early research discourse concerning the fact that computer games distract people from real life and replace them with the fictional world is now complemented by new ideas of how games expand real life. Scientific discourse and problems of game study respond to social and technical changes-the widespread expansion of the Internet, miniaturization of digital technology, the creation of new interactive game mechanics. The question of the functionality or disfunctionality of games is being solved among other things through the study of social competencies of players. The article presents an empirical test of attitudes on interpersonal relationships in the environment frequently playing a MMORPG. With the help of the questionnaire diagnostics of interpersonal relations by A.A. Rukavishnikov 43 players MMORPG and 29 non-players passed the test in our study (answers are important for the comparison of non-players data). The average age of the respondents is 33 years; the average age of non - players is 35 years. Among "inside" online games those having passed the test are more often called World of Warcraft, Travian, DoTa2, World of Tanks. Multiplayer online role-playing games are characterized by involvement in fictional worlds, recreating, for example, life in any era, they offer a player to participate in team actions. It is assumed that this experience supports the social competence of players and replenishes their social capital with new connections. The obtained empirical data support the hypothesis about the sociality of MMORPG since the communicative portrait of the average player coincides with the qualities of non-playing and is characterized by the usual for modern man orientations to participate in groups. Playing a person maintains an open network of relations, that is, accumulates social capital. The study focuses on the idea already discussed by analysts of computer games that intense gaming experience is a hobby, not dependence, and it corresponds to the way of life $\checkmark$ and the structure of free time of the modern citizen.
\end{abstract}

Key words: computer games, MMORPG, gamers, social qualities, communicative portrait, testing.

УДК 316.77

ББК 60.56

\section{«ВСТРЕТИМСЯ В ДОПОЛНЕННОЙ РЕАЛЬНОСТИ...»: СОЦИАЛЬНЫЕ КОМПЕТЕНЦИИ ИГРОКОВ В МНОГОПОЛЬЗОВАТЕЛЬСКИЕ ОНЛАЙН-ИГРЫ ${ }^{1}$}

\author{
Ольга Вячеславовна Сергеева \\ Санкт-Петербургский государственный университет, г. Санкт-Петербург, Российская Федерация \\ Анна Владиславовна Царева \\ Санкт-Петербургский государственный университет, г. Санкт-Петербург, Российская Федерация
}




\author{
Надежда Андреевна Зиновьева \\ Социологический институт ФНИСЦ РАН, г. Санкт-Петербург, Российская Федерация
}

\begin{abstract}
Аннотация. Ранний исследовательский дискурс о том, что компьютерные игры отвлекают людей от реальной жизни и заменяют их вымышленным миром, сегодня дополняется новыми идеями о том, как игры расширяют реальную жизнь. Научный дискурс и проблематика изучения игр отвечают на общесоциальные и технические изменения - повсеместное распространение Интернета, миниатюризацию цифровой техники, создание новых интерактивных игровых механик. Вопрос о функциональности или дисфункциональности игр решается в том числе благодаря исследованию социальных компетенций игроков. В статье представлены эмпирические данные тестирования ориентаций на межличностные отношения в среде часто играющих в MMORPG. С помощью опросника диагностики межличностных отношений А.А. Рукавишникова в нашем исследовании прошли испытание 43 игрока ММОРПГ и 29 неигроков (ответы неигроков важны для сопоставления данных). Средний возраст опрошенных играющих - 33 года; средний возраст неиграющих 35 лет. Среди «своих» онлайн-игр прошедшими тест чаще называются: World of Warcraft, Travian, DoTa2, World of Tanks. Многопользовательские ролевые онлайн-игры характеризуются вовлечением в вымышленные миры, воссоздающие, например, жизнь в какую-либо эпоху, они предлагают игроку участвовать в командных действиях. Предполагается, что такой опыт поддерживает социальные компетенции игроков и пополняет их социальный капитал новыми связями. Полученные эмпирические данные поддерживают гипотезу о социальности ММОРПГ, так как коммуникативный портрет среднего игрока совпадает по качествам с неиграющим и характеризуется обычными для современного человека ориентациями на участие в группах. Играя, человек поддерживает открытую для него сеть отношений, то есть накапливает социальный капитал. Проведенное исследование акцентирует идею, уже обсуждающуюся аналитиками компьютерных игр, о том, что интенсивный игровой опыт представляет собой увлечение, а не зависимость и он соответствует образу жизни и структуре свободного времени современного горожанина.
\end{abstract}

Ключевые слова: компьютерные игры, ММОРПГ, геймеры, социальные качества, коммуникативный портрет, тестирование.

\section{1. Введение}

Компьютерные игры присутствуют в наших ближайших повседневных технических устройствах уже как минимум десятилетие, изменяясь сами и меняя наш опыт. В фокусе нашего исследования - коммуникативные особенности личности в среде участников массовых многопользовательских онлайновых ролевых игр (MMOРПГ, англ. MMORPG massive/massively multiplayer online role-playing game). Рассматривая ММОРПГ как особый вид компьютерно-опосредованной коммуникации, обозначим их особенности. Такой шаг позволяет определить специфические «онлайновые» аспекты игры, значение которых форматирует практику игры, и эти же игровые аспекты сопрягаются с социальным опытом игроков:

- все социальные процессы в игре разворачиваются на символическом, нетелесном плане, созданном компьютерной технологией;

- значительна роль интерпретации и фантазии в осуществлении коммуникации и конструировании образа партнеров;
- частичная или полная анонимность участников либо псевдонимность и использование аватаров, возможность гибкого управления самопрезентацией и конструированием идентичности;

- возможность сочетания синхронной и асинхронной коммуникации, преодоление пространственных и временных ограничений взаимодействия;

- зависимость от технических характеристик компьютерных устройств и сетей.

Сегодня в популярный дискурс о том, что компьютерные игры уводят людей от реальности и замещают настоящую жизнь вымышленным миром, вливаются новые идеи, утверждающие, что игры не замещают, а дополняют реальную жизнь, расширяют и углубляют ее возможности $[5 ; 11]$. Мы придерживаемся гипотезы о том, что процесс участия в ММОРПГ выполняет социализирующую функцию, результаты которой проявляются как в пространстве онлайн-игры, так и в реальном мире. Геймеры в силу их взаимодействия в командных многопользовательских онлайн-играх проявляют социальные качества: навыки 
лидерства, способность принимать решения и брать на себя ответственность, умение действовать в условиях иерархически неравновесных взаимодействий или вести равноправные отношения, сближаться с другими и действовать в команде, ощущая принадлежность к группе. В игре возможна тренировка активной жизненной позиции, в чем немаловажным фактором является отсутствие ограничений оффлайн реальности и страха провала. Ответ на вопрос о замещении или дополнении реальности игровым опытом онлайн-игр, по нашему мнению, может быть дан благодаря исследованию социальных компетенций игроков. В данной статье мы обсуждаем результаты тестирования таких компетенций.

\section{2. Обзор литературы, посвященной исследованиям ММОРПГ}

Рассмотрим основные направления изучения многопользовательских онлайн-игр и изменения в проблематике этих исследований. $\mathrm{C}$ появлением первых многопользовательских онлайн-игр их начали рассматривать под тем же углом зрения, что и обычные (оффлайн) монопользовательские компьютерные игры, а именно: проблематизировались избегание реальности и принятия ролей в социальном окружении, стремление игрока избавиться от разного рода проблем и неприятностей, связанных с повседневной жизнью через уход в вымышленный мир игры. В фокусе исследования находились преимущественно подростки, и обсуждались причины аддикции, «игромании» (Н. Йи [27], С.К. Ло и др. [23], отечественные авторы - М.С. Иванов [7], Е.А. Лозгачева [12], С.В. Прокурова [15], Л.И. Козлова и М.Г. Чухрова [9] и др.). Ставились вопросы асоциальности, агрессивности игроков, отклоняющегося поведения в связи с увлечением онлайн-играми (К. Андерсен [19], Н. Йи [28], Е.В. Кузнецова [10]), а также изучались причины интереса к ММОРПГ, связанные с фрустрацией, страхами, депрессией, одиночеством (Т.Х. Вэй [26], О.А. Брагина [4]). В настоящее время такие исследования тоже проводятся $[6 ; 13]$.

Экспансия Интернета в повседневную жизнь изменила представления о пространстве и времени, сформировала опыт нового типа - такого, где сочетаются различные пространства (симультантность места) и ускоряется, синхронизируясь, время. Многопользовательские онлайн-игры тоже изменились: в них сегодня есть возможности для экономических действий (покупка бонусов за реальные деньги), есть командная активность для достижения игровых целей, что рождает межличностные отношения участников. ММОРПГ, таким образом, моделируют очень многие виды действий человека [8]. Изменилась и возрастная структура игроков: ММОРПГ это не «детские забавы», в них вовлечены взрослые люди.

За последние 10 лет был проведен ряд исследований, позволивших выявлять как деструктивное воздействие многопользовательских онлайн-игр на игроков, так и конструктивное. Внимание переносится на социальный аспект игры, актуализирующийся благодаря необходимости создания игровых объединений для достижения общих игровых целей. В частности, по мнению А.И. Пожарова, это подразумевает «ощущение принадлежности к группе; конкуренцию с другими подобными группами; формирование ответственности перед группой (приход в назначенное время на мероприятия, адекватное выполнение заданий и т. д.); обучение коммуникативным навыкам в иерархической или равноправной структуре, умениям подчиняться или отдавать приказы» [14, с. 272]. В ходе исследований было обнаружено, что удовольствие от социальных эффектов - дружбы и чувства общности - становится для игроков не менее важным, чем игровой азарт [25]. Кроме того, исследователи отмечали, что в ММОРПГ сегодня играют семьями и дружескими компаниями, поддерживая тем самым общность интересов (Х. Коул и М. Гриффитс [20], И. Франк и др. [21], О.А. Брагина [3]). Игры тренируют готовность преодолевать трудности и работать в команде (3.-Дж. Жонг [29], О.А. Степанцева [18]); поддерживают социальные навыки игроков (М. Гриффитс [22], О.Б. Савинская и В.А. Шоташвили [17]).

Сегодня есть данные поколенческих исследований, направленных на когорты, чья социализация прошла в эпоху массового распространения компьютерных игр. Американские ученые Дж. Бек и М. Уэйд [2] пишут о пре- 
имуществах, которые поколение «геймеров» приобрело по сравнению с поколением своих родителей. В компьютерных играх нет ограничений и нет страха бесповоротного провала. В крайнем случае игру можно перезапустить или начать следующую, в которой все удастся. В играх нет безвыходных ситуаций, что формирует у игрока позитивную установку. Азарт игры и целедостижения не только выполняет компенсаторную функцию, но и позволяет игрокам чувствовать себя увереннее в жизни и добиваться поставленных целей. Авторы делают вывод о том, что миры, создаваемые в компьютерных играх, функционируют как обучающие ситуации, готовящие к действиям в реальных организациях.

Мы видим, что взгляды ученых на многопользовательские онлайн-игры менялись с течением времени по мере общесоциальных и технических изменений (повсеместное распространение Интернета, миниатюризация цифровой техники), а также по мере создания новых интерактивных игровых механик. Актуальные работы все чаще обращают внимание на функционирование ММОРПГ как досуговых клубов, объединяющих игроков не только в виртуальном пространстве, но и за пределами него для разнообразных социальных коммуникаций.

\section{3. Характеристика метода исследования}

\section{1. О специфике теста}

Интерес к тому, каковы личностные качества игроков ММОРПГ (а именно социальные компетенции) закономерно привел нас к измерению их с помощью тестирования. Как пишет В.С. Аванесов, автор работы о применении тестов в социологии, «если в социологическом исследовании появляется необходимость оценить связь личностных качеств респондентов с их поступками, делами... то для этой цели могут быть использованы некоторые тесты, имеющиеся у психологов» [1, c. 38]. Нам было важно понять, какие типы личности распространены в среде тех, кто регулярно практикует многопользовательские ролевые онлайн-игры. Желая проверить, связан ли опыт игры с какими-либо специфическими качествами личности, проявляющими- ся, прежде всего, в интеракции, мы и обратились к процедурам тестирования.

Первая треть XX в. - это эпоха оформления тестовой традиции в социальных исследованиях. Так, в 1933 г. было принято одно из самых корректных, по нашему мнению, определений данного метода: «Тест - это испытание, включающее в себя выполнение определенной задачи, идентичной для всех обследуемых субъектов, с применением точной техники для оценки успеха или неудачи или же для числовой записи результатов» $[16$, с. 468$]$. Использованный нами опросник диагностики межличностных отношений А.А. Рукавишникова предназначен для оценки типичных способов отношения респондента к другим людям. Данный тест является адаптацией распространенного в зарубежной практике опросника FIRO (Fundamental Interpersonal Relations Orientation), автор которого - американский психолог В. Шутц [24]. Тест FIRO создавался для людей без учета их увлеченности многопользовательскими играми, что позволило провести стандартные замеры социальности личности и выявить, в какой степени игроки, постоянно играющие в онлайн-игры, обладают навыками общения в повседневной жизни.

Тест Руквишникова проверяет ориентации личности на других людей, то есть на его основе определяется поддерживаемый человеком тип межличностного взаимодействия. Тест выявляет три значимые области ориентации личности: «ориентация на включение во взаимодействия с другими» (I, Inclusion), «ориентация на контроль групповых правил» (C, Control) и «ориентация на эмоциональные контакты с другими» (A, Affection). Причем тестируются два аспекта каждой из области ориентаций: выраженное поведение индивида (expressed) и требуемое индивидом поведение окружающих (wanted). Всего в опроснике - 54 утверждения, требующие от испытуемого выбрать один из ответов в рамках шестибалльной оценочной шкалы. Наш тест-опрос был дополнен вопросам об игровом опыте респондентов: как давно они играют, в какие игры и как часто они играют, а также социально-демографическими данными. К тестированию были привлечены и неигроки с тем, чтобы сопоставить социальные компетенции увлеченных и не увлеченных играми. 


\section{2. Сбор данных и их обработка}

Тестирование игроков старше 18 лет, играющих в ММОРПГ не реже одного раза в неделю, проводилось с лета 2016 по начало 2017 года. Для выявления того, насколько постоянно играющие в ММОРПГ действительно обладают развитыми социальными качествами в повседневной жизни, вопросы теста были размещены в Google Groups. Для распространения ссылки на тест был найден волонтер, играющий в Travian, который привлек к тестированию других играющих методом «снежного кома». Выборка - целенаправленная, так как тестирование проходили люди, удовлетворяющие ряду параметров - только взрослые, часто играющие в ММОРПГ. Опросник был распространен также среди взрослых людей, не играющих вообще ни в какие видеоигры. В итоге тестирование прошли 43 игрока и 29 неигроков.

Обработка данных проводилась с помощью программы Excel. Полученные данные анализировались в двух срезах: общий массив данных для выявления тенденций и предрасположенностей в группе игроков (при сравнении их с неиграющими) и индивидуальные профили опрошенных.

\section{4. Коммуникативный портрет игрока в сравнении с неигроком: результаты исследования}

В зависимости от того, как часто человек играет, испытуемых можно разделить на две группы: 1) играющие ежедневно (28 человек), 2) играющие не реже одного раза в неделю (15 человек). Игровой стаж респондентов - от 1 года до 20 лет (отмечался общий опыт, куда вошли видеоигры в целом, не только ММОРПГ). Среди «своих» онлайн-игр прошедшими тест чаще называются: World of Warcraft, Travian, DoTa2, World of Tanks, Lineage 2, League of Legends.

Большинство игроков (65\%) имеют высшее или неоконченное высшее образование, учатся в вузе - $12 \%$, остальные получили средне-специальное образование - $23 \%$. Среди неиграющих: 79 \% - с высшим образованием и $21 \%$ - со средне-специальным. Игроки - люди разных профессий и сфер занятос- ти, среди которых были названы: геолог, юрист, менеджер, строитель, инженер, системный администратор, фрилансер, психотерапевт, сиделка, закройщик, бухгалтер, экономист, госслужащий, продавец и др.

Средний возраст играющих - 33 года; средний возраст неиграющих - 35 лет.

Взгляд на группу в целом достигается подсчетом средних значений по каждой из шести шкал ( $\mathrm{Ie}, \mathrm{Iw}, \mathrm{Ce}, \mathrm{Cw}, \mathrm{Ae}, \mathrm{Aw})$. Таким образом, мы создаем портрет «среднего игрока». Уточнить, насколько типично среднее значение ориентаций на групповую включенность, стремление к контролю и поддержке эмоциональных контактов, помогает подсчет стандартных отклонений. Для «среднего игрока», прошедшего тестирование, характерны следующие ориентации в социальном поведении (см. табл. 1).

Значения стандартных отклонений невелики (чуть больше стандартное отклонение у Iw), то есть баллы игроков характеризуются низкой вариабельностью, и средний балл корректно репрезентирует баллы игроков. Мы также сопоставляем средние баллы игроков с неигроками, здесь стандартное отклонение вообще не превышает 2,1 (см. табл. 2).

На рисунке 1 хорошо видно отсутствие принципиальных отличий в поведении среднего игрока и среднего неиграющего при включении в группу, контроле действий своих и окружающих и стремлении к эмоциональным контактам. Подсчитанные нами средние баллы по всем шкалам как у игроков ММОРПГ, так и у неиграющих демонстрируют либо переходные значения баллов от низких к высоким (4-5), либо низкие (близки к 3). На фоне всех баллов выделяются чуть более высокие по шкале стремления влиять на других и брать руководство на себя (у игроков $-\mathrm{Ce}=5,3 ;$ у неиграющих $-\mathrm{Ce}=5,8)$. При этом как средний игрок, так и неиграющий проявляют низкое стремление к тесным отношениям с окружающими (у игроков $-\mathrm{Ae}=3,3$; у неиграющих $-\mathrm{Ae}=3,4)$.

Предпочитаемая средним игроком и средним неиграющим интенсивность взаимодействий по удовлетворению межличностной потребности включения в группу, контролю действий и стремлению к тесным контактам, называемая индексом объема интеракций, 
Средний балл группы протестированных игроков

\begin{tabular}{|l|c|c|c|c|c|c|}
\hline \multirow{2}{*}{ Значение } & \multicolumn{2}{|c|}{$\begin{array}{c}\text { Стремление } \\
\text { принадлежать } \\
\text { к различным группам }\end{array}$} & \multicolumn{2}{|c|}{$\begin{array}{c}\text { Стремление влиять } \\
\text { на других vs. } \\
\text { подчиняться другим }\end{array}$} & $\begin{array}{c}\text { Стремление к близким } \\
\text { эмоциональным } \\
\text { отношениям }\end{array}$ \\
\cline { 2 - 7 } & $\mathrm{Ie}$ & $\mathrm{Iw}$ & $\mathrm{Ce}$ & $\mathrm{CW}$ & $\mathrm{Ae}$ & $\mathrm{Aw}$ \\
\hline Среднее & 4,3 & 4,8 & 5,3 & 3,8 & 3,3 & 4 \\
\hline $\begin{array}{l}\text { Стандартное } \\
\text { отклонение }\end{array}$ & 1,8 & 2,9 & 2,4 & 2,1 & 1,6 & 2,1 \\
\hline
\end{tabular}

Таблииа 2

Средний балл группы протестированных неиграющих

\begin{tabular}{|l|c|c|c|c|c|c|}
\hline \multirow{2}{*}{ Значение } & \multicolumn{2}{|c|}{$\begin{array}{c}\text { Стремление } \\
\text { принадлежать } \\
\text { к различным группам }\end{array}$} & \multicolumn{2}{c|}{$\begin{array}{c}\text { Стремление влиять } \\
\text { на других vs. } \\
\text { подчиняться другим }\end{array}$} & $\begin{array}{c}\text { Стремление к близким } \\
\text { эмоциональным } \\
\text { отношениям }\end{array}$ \\
\cline { 2 - 7 } & $\mathrm{Ie}$ & $\mathrm{Iw}$ & $\mathrm{Ce}$ & $\mathrm{CW}$ & $\mathrm{Ae}$ & $\mathrm{Aw}$ \\
\hline Среднее & 3,9 & 3,9 & 5,8 & 4,3 & 3,4 & 3,7 \\
\hline $\begin{array}{l}\text { Стандартное } \\
\text { отклонение }\end{array}$ & 1,3 & 2,1 & 1,34 & 2 & 1,7 & 1,9 \\
\hline
\end{tabular}

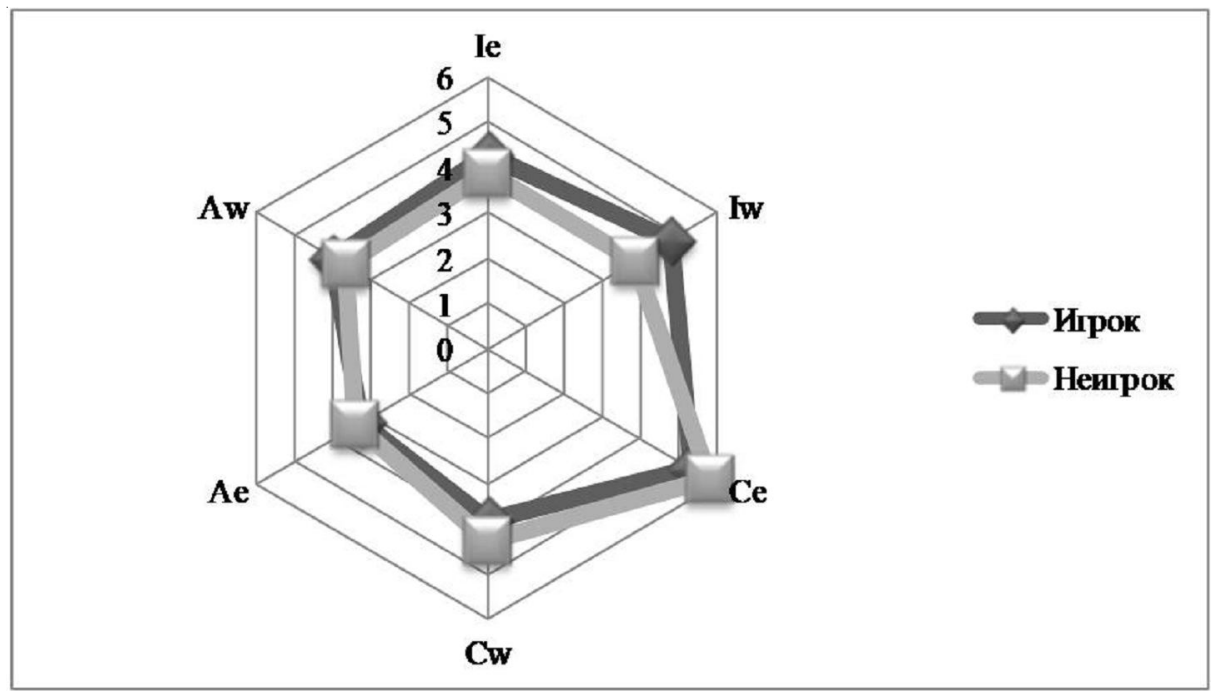

Рис. 1. Сравнение средних баллов в ориентациях игрока и неиграющего

представлена в таблице 3. Индекс рассчитывается как $\mathrm{e}+\mathrm{W}$ и может варьировать от 0 до 18. Мы отмечаем в полученных нами индексах объема интеракций отсутствие принципиальных отличий между постоянно играющими в ММОРПГ и обычными людьми.

Помимо индекса объема интеракций наши тестовые данные позволяют оценить индекс противоречивости межличностного поведения. Этот индекс квалифицирует разрыв между собственным поведением человека и предъявляемыми им требованиями к поведению окружающих. Значение индекса может варьировать от 0 до 9. Чем ближе значение индекса к 9 , тем больше разрыв и вероятность неудовлетворенности в каком-либо виде социальных устремлений. Однако в нашем случае таблица 4 показывает сбалансированность поведения и игроков, и неигроков, при этом индексы обеих протестированных групп практически тождественны.

На рисунке 2 приведены сводные данные всех 43 игроков, отметивших ту или иную степень значимости (от 0 до 9) типичных для них способов взаимодействия с людьми. И здесь мы еще раз видим, что многие не придают большого значения созданию и поддержке эмоционально насыщенных от- 
Индекс объема интеракций у среднего игрока и неиграющего

\begin{tabular}{|l|c|c|c|}
\hline \multicolumn{1}{|c|}{ Группа } & $\begin{array}{c}\mathrm{I}(\mathrm{e}+\mathrm{W}) \text { стремление } \\
\text { принадлежать } \\
\text { к различным группам }\end{array}$ & $\begin{array}{c}\mathrm{C}(\mathrm{e}+\mathrm{W}) \\
\text { стремление } \\
\text { к влиянию }\end{array}$ & $\begin{array}{c}\mathrm{A}(\mathrm{e}+\mathrm{W}) \text { стремление } \\
\text { к близким эмоциональным } \\
\text { отношениям }\end{array}$ \\
\hline Игроки & 9,1 & 9,1 & 7,3 \\
\hline Неиграющие & 7,8 & 9,1 & 7,1 \\
\hline
\end{tabular}

Таблица 4

Индекс противоречивости межличностного поведения у среднего игрока и неиграющего

\begin{tabular}{|l|c|c|c|}
\hline \multicolumn{1}{|c|}{ Группа } & $\begin{array}{c}\text { I (е - W) стремление } \\
\text { принадлежать } \\
\text { к различным группам } \\
\text { и ожидание этого от других }\end{array}$ & $\begin{array}{c}\text { C (е - W) стремление } \\
\text { к влиянию и ожидание } \\
\text { контроля со стороны } \\
\text { других }\end{array}$ & $\begin{array}{c}\text { А (е - W) стремление } \\
\text { близким эмоциональным } \\
\text { отношениям и ожидание } \\
\text { этого от других }\end{array}$ \\
\hline Игроки & $-0,5$ & 1,5 & $-0,7$ \\
\hline Неиграющие & 0 & 1,5 & $-0,3$ \\
\hline
\end{tabular}

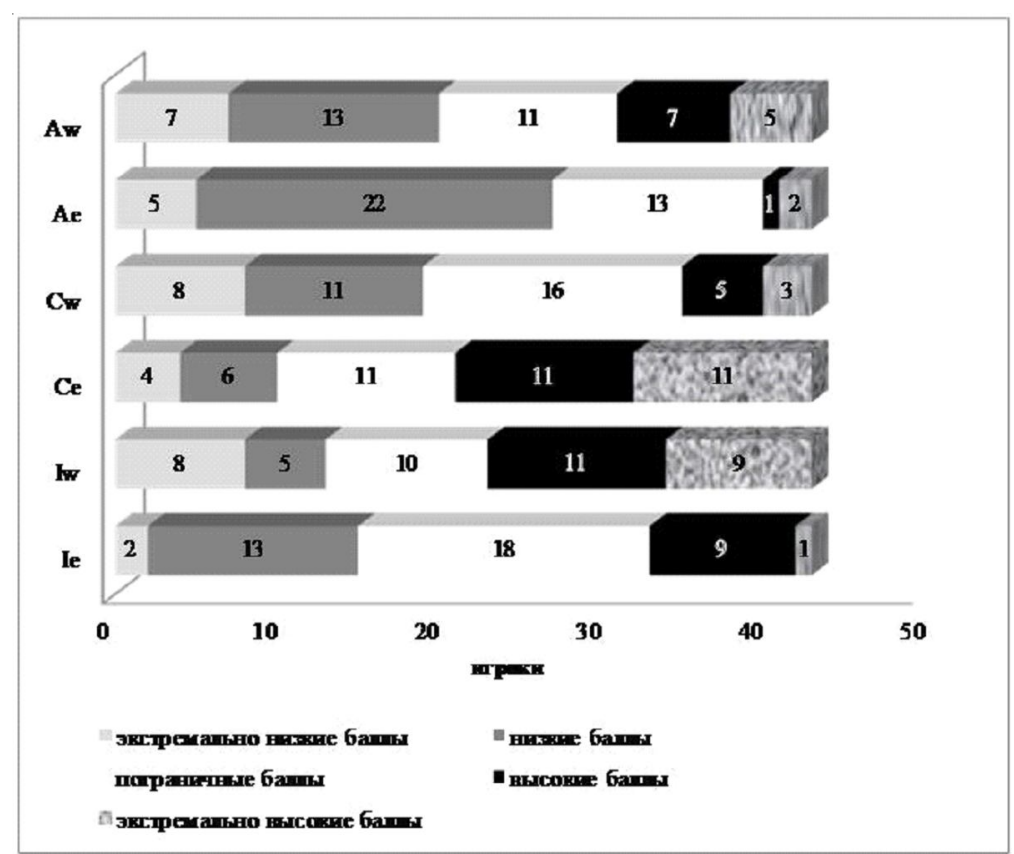

Рис. 2. Социальные компетенции игроков (43 человека)

ношений со своим окружением (Ае). Наряду с этим половина протестированных игроков стремится лидировать в группе (Се), но при этом ждет от других приглашения участвовать в чем-либо (Iw).

Располагая данными о каждом отдельном игроке и неигроке, мы обратили внимание на индивидуальные профили тех, кто играет ежедневно не менее двух часов в день. Логика отдельного обращения к часто играющим обусловлена предположением об их возможной асоциальности, социальной несостоятельности. Таких игроков сре- ди прошедших тестирование было 18 человек (см. табл. 5).

Игроки, тратящие значительное время на ММОРПГ, не выделяются своими коммуникативными качествами (рисунок 3 визуализирует эту ситуацию).

Из 18 часто и интенсивно играющих 7 человек женаты или замужем, двое имеют статус руководителей, один является предпринимателем. Руководители и предприниматель отличаются выраженным поведением в области контроля, стремятся брать ответственность в группе на себя $(\mathrm{Ce}=8)$. 
Средний балл игроков, играющих ежедневно два часа и более

\begin{tabular}{|l|c|c|c|c|c|c|}
\hline \multirow{2}{*}{ Значение } & \multicolumn{2}{|c|}{$\begin{array}{c}\text { Стремление } \\
\text { принадлежать } \\
\text { к различным группам }\end{array}$} & \multicolumn{2}{|c|}{$\begin{array}{c}\text { Стремление влиять } \\
\text { на других vs. } \\
\text { подчиняться другим }\end{array}$} & $\begin{array}{c}\text { Стремление к близким } \\
\text { эмоциональным } \\
\text { отношениям }\end{array}$ \\
\cline { 2 - 7 } & $\mathrm{Ie}$ & $\mathrm{Iw}$ & $\mathrm{Ce}$ & $\mathrm{CW}$ & $\mathrm{Ae}$ & $\mathrm{Aw}$ \\
\hline Среднее & 4 & 4,6 & 5,2 & 4,6 & 3,7 & 4,3 \\
\hline $\begin{array}{l}\text { Стандартное } \\
\text { отклонение }\end{array}$ & 2,2 & 2,9 & 2,7 & 2,2 & 1,5 & 2,7 \\
\hline
\end{tabular}
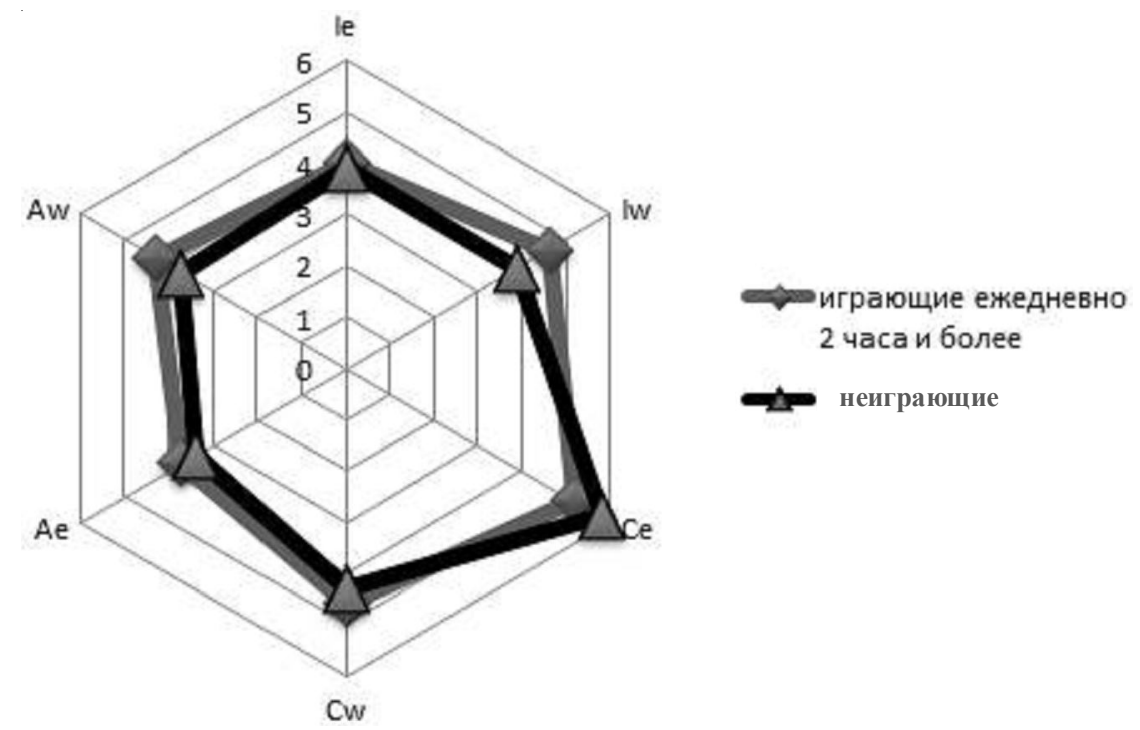

Рис. 3. Сравнение средних баллов в ориентациях часто играющего и неиграющего

\section{5. Обсуждение результатов}

Метод тестирования позволил выявить социальные компетенции игроков ММОРПГ и сравнить их с качествами неиграющих. Рассчитав средние значения по областям устремлений (включение, контроль, эмоциональность), мы разработали коммуникативный портрет игрока. Игрок ММОРПГ не избегает социальных контактов, хотя склонен занимать выжидательную позицию, рассчитывая на приглашение к участию в чемлибо; показывает обычную активность и стремление руководить группой; не всегда настроен на эмоционально близкие контакты и не ждет такого поведения от других. Данный тип поведения не отличается от установленных при тестировании ориентаций неиграющего. И даже отдельно рассмотренные испытуемые, ежедневно играющие более двух часов, не демонстрируют склонности к избеганию включения в группу и социальной пассивности.
Объясняя отсутствие каких-либо экстремальных баллов, характеризующих межличностное поведение игроков, мы обращаемся к специфике многопользовательских ролевых онлайн-игр. Стоит отметить, что в условиях игрового взаимодействия между игроками поддерживаются навыки и модели взаимодействия, нацеленные на совместное выполнение внутриигровых задач, формирование общего опыта и создание сетей взаимодействия с другими участниками таких сообществ. ММОРПГ - коммуникативное пространство, обладающее социализирующими возможностями и ресурсами накопления социального капитала игроков, хотя особенности этих коммуникаций обусловлены игровой механикой. Программное обеспечение различных видов игр формирует для игроков возможности и ограничения в коммуникации, установления групповых отношений и выполнения совместных организованных действий.

Чтобы понять специфику ММОРПГ на фоне других игр, выделим два типа игр, кото- 
рые условно назовем играми «активного вовлечения» (внешний локус контроля) и играми «инициативного вовлечения» (внутренний локус контроля). Эта типология игр позволяет учитывать такие значимые характеристики игровой коммуникации, как жесткость соблюдения правил игрового взаимодействия, активность или пассивность игроков в определении игровых целей и направленности своих действий, возможности инициативы и творчества в реализации игровых задач, ориентацию на себя или других игроков и т. д.

Говоря об играх активного вовлечения, мы имеем в виду тип игр, предполагающих хорошо идентифицируемые внешние стимулы, которые постоянно мотивируют игрока продолжать играть. Например, в ходе игры необходимо преодолевать постоянно появляющиеся препятствия, ловить врага и т. п. Игровое действие здесь - ответ на «выпад» игровой реальности. Это, например, игры аркадного типа, шутеры и экшены и пр.

В играх инициативного вовлечения стимулы к игровой деятельности носят не непосредственно предметный, а символический характер. Это означает, что игрок переживает некоторую ситуацию в вымышленном мире и его действия представляют собой не реакцию на непосредственный раздражитель (удар, падение и т. п.), а исполнение роли в развитии сюжета. К играм подобного типа относятся текстовые многопользовательские игровые миры, сетевые симуляторы, игры стратегического действия, ролевые игры и пр.

Игры активного и инициативного вовлечения, таким образом, представляют два качественно различных способа конструирования социального и психического опыта игроков, это разные формы инициативы, принятия решений, условий и целей индивидуальной и групповой активности, интереса к сотрудничеству. Одним из основных факторов привлекательности ММОРПГ является то, что они дают возможности играть в реальном времени с другими игроками, осуществлять реальное взаимодействие в рамках виртуального игрового мира и реализовывать в компьютерно-опосредованной игровой среде отношения конкуренции, сотрудничества, целедостижения. Многие из таких игр основаны на принципах захвата и удержании территории, когда один человек не может достичь результата, а выигрыш зависит от сплоченности и сыгранности команды. Это побуждает игроков объединяться в постоянные команды, «кланы» и выстраивать внутри коллектива успешную коммуникацию. Игрокам необходимо эффективно договариваться, слаженно поступать, вести за собой, брать на себя ответственность, вносить свой вклад в общую победу. Немаловажными в таких играх являются и способности стратегического мышления, помогающие выстроить общие действия, приводящие команду к выигрышу. Возможность переговариваться во время игровой сессии подкрепляет командные связи. Потому участвовавшие в исследовании игроки, чей игровой опыт связан с играми инициативного вовлечения, не демонстрируют социальной эксклюзии, они ориентированы на включение в группы.

Мы согласны с идеей московских социологов О.Б. Савинской и В.А. Шоташвили о различиях между зависимостью и увлеченностью, когда речь идет об игроках $[17$, с. 125$]$. Поглощенность игрой, затрачиваемое на нее время - это все то, что обычно характеризует увлеченного, а не обязательно зависимого, потерявшего контроль человека. Тем более что игры сегодня мобильны, переход к игре не требует некоторого специально выделенного времени, а может происходить в те промежутки времени, которые раньше вынужденно тратились без занятий, например поездка в транспорте, очередь и т. п. ситуации.

\section{6. Заключение}

Современные многопользовательские компьютерные онлайн-игры представляют собой социальное пространство, где востребованы социальные компетенции играющих в них. На основе тестирования ориентиров на межличностные отношения создается коммуникативный портрет среднего игрока, а его сравнение с портретом неиграющего обогащает понимание опыта игры не как зависимости, но как увлечения. В ходе нашего исследования у игроков ММОРПГ были выявлены такие важные для успешной социальной адаптации качества, как стремление контролировать собственные действия, ориентация 
на сотрудничество с другими, хотя и при низкой заинтересованности в эмоционально насыщенных отношениях. Среди опрошенных есть много лидеров, поскольку в отношении контроля и власти преобладает ориентация на себя, а не на других. В то же время в индивидуальных стратегиях выстраивания межличностных отношений и включенности в группу наблюдается незначительное преобладание ожиданий от других («требуемое» поведение) над готовностью к собственным действиям («выраженное» поведение).

Взаимодействие в социальной сети (например, через MMORPG) позволяет поддерживать социальный капитал. Будучи членом игровой группы (клана), игрок накапливает дружеско-приятельские отношения через открытую для него сеть. Это преимущества и возможности, полученные от принадлежности к определенному сообществу, и это также основа для коллективных действий.

\section{ПРИМЕЧАНИЕ}

1 Работа выполнена при финансовой поддержке РФФИ в рамках научного проекта «Естественнонаучные методы в исследованиях игрового компьютерного опыта» № 16-06-00368 а.

\section{СПИСОК ЛИТЕРАТУРЫ}

1. Аванесов, В. С. Тесты в социологическом исследовании / В. С. Аванесов. - М. : Наука, 1982.$199 \mathrm{c}$.

2. Бек, Дж. Доигрались! Как поколение геймеров навсегда меняет бизнес-среду / Дж. Бек, М. Уэйд. - М. : Претекст, 2006. - 252 с.

3. Брагина, О. А. Анализ научных представлений об отдельных индивидуально-личностных факторах, определяющих вовлеченность в массовые многопользовательские ролевые онлайн-игры / О. А. Брагина // Вестник Саратовского областного института развития образования. - 2015. - № 1.C. 94-101.

4. Брагина, О. А. Одиночество как значимый фактор формирования зависимости от многопользовательских ролевых онлайн-игр / О. А. Брагина // Пензенский психологический вестник. - 2015. № 2. - С. 77-85.

5. Вахштайн, В. С. Компьютерные игры: взгляд социолога / В. С. Вахштайн. - Электрон. текстовые дан. - Режим доступа: http://arzamas.academy/ materials/947 (дата обращения: 04.12.2017). - Загл. с экрана.

6. Заборников, А. Е. Зависимость от интернет-игр как фактор, влияющий на становление личности подростка / А. Е. Заборников, А. Г. Абросимов // Известия Института систем управления СГЭУ. - 2015. - № 1 (11). - С. 323-327.

7. Иванов, М. С. Психологические аспекты негативного влияния игровой компьютерной зависимости на личность человека / М. С. Иванов // Психология зависимости : хрестоматия / сост. К. В. Сельченок. - Минск : Харвест, 2004. - С. 223-230.

8. Игнатьев, В. И. «Дополненное» социальное пространство: сети и структуры «second life» / В. И. Игнатьев, С. А. Кузин // Идеи и идеалы. 2014. - № 4 (22). - С. 100-114.

9. Козлова, Л. И. Личностные характеристики пользователей сети Интернет, склонных к зависимости от многопользовательских ролевых онлайн-игр / Л. И. Козлова, М. Г. Чухрова // Мир науки, культуры, образования. - 2012. - № 3 (34). - С. 193-195.

10. Кузнецова, Е. В. Некоторые аспекты влияния онлайн и сетевых игр на формирование девиантного поведения несовершеннолетних / Е. В. Кузнецова // Вестник Московского университета МВД России. - 2014. - № 10. - С. 85-88.

11. Куренной, B. Pokemon Go как общественный феномен / В. Куренной. - Электрон. текстовые дан. - Режим доступа: https://theoryandpractice.ru/ videos/1087-vitaliy-kurennoy-pokemon-go-kakobshchestvennyy-fenomen (дата обращения: 04.12.2017). - Загл. с экрана.

12. Лозгачева, Е. А. Игровая зависимость: особенности и социальные последствия / Е. А. Лозгачева // Мониторинг общественного мнения: экономические и социальные перемены. - 2008. № 3 (87). - С. 126-133.

13. Маринова, Т. Ю. Социально-психологические аспекты зависимости от компьютерных многопользовательских ролевых онлайн-игр / Т. Ю. Маринова, О. В. Зарецкая // Социальная психология и общество. - 2015. - Т. 6, № 3. - С. 109-119.

14. Пожаров, А. И. Многопользовательская ролевая онлайн-игра как новый вид культурной коммуникации / А. И. Пожаров // Историческая и социально-образовательная мысль. - 2014. - Т. 6 , № 6-2 (28). - С. 270-273.

15. Прокурова, С. В. Компьютерная и игровая зависимость и профилактическая деятельность по ее преодолению / С. В. Прокурова // Современные проблемы науки и образования. - 2015. - № 2. C. 566.

16. Пэнто, Р. Методы социальных наук / Р. Пэнто, М. Гравитц. - М. : Прогресс, 1972. - 607 с.

17. Савинская, О. Б. Влияние увлеченности онлайн-играми на интенсивность коммуникаций 
и социальные навыки игроков / О. Б. Савинская, В. А. Шоташвили // Мониторинг общественного мнения. - 2013. - № 5 (117). - С. 123-135.

18. Степанцева, О. А. Субкультура геймеров в контексте информационного общества : автореф. дис. ... канд. культурологии / Степанцева Ольга Александровна. - СПб. : Санкт-Петерб. гос. гуманит. унт профсоюзов, 2007. - 27 c.

19. Anderson, C. A. Video games and aggressive thoughts, feelings, and behavior in the laboratory and in life / C. A. Anderson, K. E. Dill // Journal of Personality and Social Psychology. - 2000. - Vol. 78, № 4. - P. 772-790.

20. Cole, H. Social interactions in massively multiplayer online role-playing gamers / H. Cole, M. D. Griffiths // CyberPsychology \& Behavior. 2007. - Vol. 10, № 4. - P. 575-583.

21. Frank, I. Some positive effects of online gaming / I. Frank, N. Sanbou, K. Terashima // Proceedings of the international conference on Advances in computer entertainment technology (ACE'06). - N. Y. : ACM, 2006. - Article 73. - Electronic text data. - Mode of access: http://doi.acm.org/10.1145/ 1178823.1178909 (date of access: 04.12.2017). - Title from screen.

22. Griffiths, M. Computer game playing and social skills: a pilot study / M. Griffiths // Aloma : Revista de Psicologia, Ciències de l'Educaciy i de l’Esport. - 2010. - № 27. - P. 301-310.

23. Lo, S. K. Physical interpersonal relationships and social anxiety among online game players / S. K. Lo, C. C. Wang, W. Fang // CyberPsychology \& Behavior. - 2005. - Vol. 8, № 1. - P. 15-20.

24. Schutz, W. The Interpersonal Underworld /W. Schutz. - Palo Alto : Science and Behavior Books, 1966. $-242 \mathrm{p}$.

25. Sublette, V. A. Consequences of Play: A Systematic Review of the Effects of Online Gaming / V. A. Sublette, B. Mullan // International Journal of Mental Health and Addiction. - 2012. - Vol. 10, № 1.P. 3-23.

26. The association between online gaming, social phobia, and depression : an internet survey / H.-T. Wei, M.-H. Chen, P.-Ch. Huang, Y.-M. Bai // BMC psychiatry. - 2012. - Vol. 12, № 1. - P. 92.

27. Yee, N. The demographics, motivations, and derived experiences of users of massively multi-user online graphical environments / N. Yee // Presence: teleoperators and virtual environments. - 2006. Vol. 15, № 3. - P. 309-329.

28. Yee, N. Understanding MMORPG addiction / N. Yee. - Electronic text data. - Mode of access: http://www.nickyee.com/hub/addiction/addiction.pdf (date of access: 04.12.2017). - Title from screen.

29. Zhong, Z.-J. The effects of collective MMORPG play on gamers online and offline social capital / Z.-J. Zhong // Computers in Human Behavior. - 2011. - Vol. 27, № 6. - P. 2352-2363.

\section{REFERENCES}

1. Avanesov V.S. Testy v sotsiologicheskom issledovanii [Tests in Sociological Research]. Moscow, Nauka Publ., 1982. 199 p.

2. Bek J., Wade M. Doigralis! Kak pokolenie geymerov navsegda menyaet biznes-sredu [Got Game: How the Gamer Generation is Reshaping Business Forever]. Moscow, Pretekst Publ., 2006. 252 p.

3. Bragina O.A. Analiz nauchnykh predstavleniy ob otdelnykh individualno-lichnostnykh faktorakh, opredelyayushchikh vovlechennost $\mathrm{v}$ massovye mnogopolzovatelskie rolevye onlayn-igry [The Analysis of Scientific Ideas about Individual Personality Determing the Involvement in Mass Multiplayer Online Games]. Vestnik Saratovskogo oblastnogo instituta razvitiya obrazovaniya, 2015, no. 1, pp. 94-101.

4. Bragina O.A. Odinochestvo kak znachimyy faktor formirovaniya zavisimosti ot mnogopolzovatelskikh rolevykh onlayn-igr [Loneliness as a Significant Factor in the Formation of Addiction to Multiplayer Online RoleGames]. Penzenskiy psikhologicheskiy vestnik, 2015, no. 2, pp. 77-85.

5. Vakhshtayn V. Kompyuternye igry: vzglyad sotsiologa [Computer Games: Sociologist's Opinion]. URL: http://arzamas.academy/materials/947. (accessed December 4, 2017).

6. Zabornikov A.E., Abrosimov A.G. Zavisimost ot internet-igr kak faktor, vliyayushchiy na stanovlenie lichnosti podrostka [Addiction to Online Games as a Factor Influencing the Personality of a Teenager]. Izvestiya Instituta sistem upravleniya SGEU, 2015, no. 1 (11), pp. 323-327.

7. Ivanov M.S. Psikhologicheskie aspekty negativnogo vliyaniya igrovoy kompyuternoy zavisimosti na lichnost cheloveka [Psychological Aspects of the Negative Influence of Game Addiction on the Personal Identity]. Selchenok K.V., ed. Psikhologiya zavisimosti: khrestomatiya [Psychology of Addiction. Anthology]. Minsk, Kharvest Publ., 2004, pp. 223-230.

8. Ignatyev V.I., Kuzin S.A. «Dopolnennoe» sotsialnoe prostranstvo: seti i struktury «second life» ["Augmented" Social Space: Networks and Structures of "Second Life"]. Idei i idealy, 2014, no. 4 (22), pp. 100-114.

9. Kozlova L.I., Chukhrova M.G. Lichnostnye kharakteristiki polzovateley seti internet, sklonnykh k zavisimosti ot mnogopolzovatelskikh rolevykh onlaynigr [Personality Characteristics of Internet Users Subject to Addiction to Mass Multiplayer Online Role- 
Playing Games]. Mir nauki, kultury, obrazovaniya, 2012, no. 3 (34), pp. 193-195.

10. Kuznetsova E.V. Nekotorye aspekty vliyaniya onlayn i setevykh igr na formirovanie deviantnogo povedeniya nesovershennoletnikh [Some Aspects of Influence of Online and Network Games on Deviant Behavior in Minors]. Vestnik Moskovskogo universiteta MVD Rossii, 2014, no. 10, pp. 85-88.

11. Kurennot V. Pokemon Go kak obshchestvennyy fenomen [Pokemon Go as a Social Phenomenon]. URL: https://theoryandpractice.ru/videos/1087-vitaliykurennoy-pokemon-go-kak-obshchestvennyy-fenomen. (accessed December 4, 2017).

12. Lozgacheva E.A. Igrovaya zavisimost: osobennosti i sotsialnye posledstviya [Game Addiction: Features and Social Consequences]. Monitoring obshchestvennogo mneniya: ekonomicheskie $i$ sotsialnye peremeny, 2008, no. 3 (87), pp 126-133.

13. Marinova T.Yu., Zaretskaya O.V. Sotsialnopsikhologicheskie aspekty zavisimosti ot kompyuternykh mnogopolzovatelskikh rolevykh onlayn-igr [Social and Psychological Aspects of MMORPG Addiction]. Sotsialnaya psikhologiya $i$ obshchestvo, 2015, no. 6(3), pp. 109-119.

14. Pozharov A.I. Mnogopolzovatelskaya rolevaya onlayn-igra kak novyy vid kulturnoy kommunikatsii [Multiplayer Online Role-Playing Game as a New Type of Cultural Communication]. Istoricheskaya i sotsialno-obrazovatelnaya mysl, 2014, no. 6, pp. 270-273.

15. Prokurova S.V. Kompyuternaya i igrovaya zavisimost i profilakticheskaya deyatelnost po ee preodoleniyu [Computer and Game Addiction and Preventive Activity to Overcome It]. Sovremennye problemy nauki i obrazovaniya, 2015, no. 2 (2), p. 566.

16. Pjento R., Gravitc M. Metody sotsialnykh nauk [Methods of Social Sciences]. Moscow, Progress Publ., 1972. 607 p.

17. Savinskaya O.B., Shotashvili V.A. Vliyanie uvlechennosti onlayn-igrami na intensivnost kommunikatsiy i sotsialnye navyki igrokov [Influence of online gaming addiction on the communication intensity and social skills of gamers]. Monitoring obshchestvennogo mneniya: ekonomicheskie $i$ sotsialnye peremeny, 2013, no. 5 (117), pp. 123-134.

18. Stepantseva O.A. Subkultura geymerov $v$ kontekste informatsionnogo obshchestva: avtoref. dis. ... kand. kultur. nauk [Gamers Subculture in the Context of Information Society. Cand. cultural studies sci. diss.]. Saint Petersburg, 2007. 27 p.

19. Anderson C.A., Dill K.E. Video games and aggressive thoughts, feelings, and behavior in the laboratory and in life. Journal of Personality and Social Psychology, 2000, no. 4 (78), pp. 772-790.

20. Cole H., Griffiths M.D. Social interactions in massively multiplayer online role-playing gamers. CyberPsychology \& Behavior, 2007, no. 4 (10), pp. 575-583.

21. Frank I., Sanbou N., Terashima K. Some positive effects of online gaming. Proceedings of the international conference on Advances in computer entertainment technology (ACE '06). New York, ACM, 2006. Article 73. URL: http://doi.acm.org/10.1145/ 1178823.1178909. (accessed December 4, 2017).

22. Griffiths M. Computer game playing and social skills: a pilot study. Aloma: Revista de Psicologia, Ciuncies de l'Educaciy $i$ de l'Esport, 2010, no. 27, pp. 301-310.

23. Lo S. K., Wang C. C., Fang W. Physical interpersonal relationships and social anxiety among online game players. CyberPsychology \& Behavior, 2005, no. 1 (8), pp. 15-20.

24. Schutz W. The Interpersonal Underworld. Palo Alto, Science and Behavior Books, 1966. 242 p.

25. Sublette V. A., Mullan B. Consequences of Play: A Systematic Review of the Effects of Online Gaming. International Journal of Mental Health and Addiction, 2012, no.1 (10), pp. 3-23.

26. Wei H. T., Chen M.H., Huang P.C., Bai Y.M. The association between online gaming, social phobia, and depression: an internet survey. BMC psychiatry, 2012, no. 1 (12). URL: https://www.ncbi.nlm.nih.gov/pmc/ articles/PMC3545926/. (accessed December 4, 2017).

27. Yee N. The demographics, motivations, and derived experiences of users of massively multi-user online graphical environments. Presence: teleoperators and virtual environments, 2006, no. 3 (15), pp. 309-329.

28. Yee N. Understanding MMORPG addiction. URL: http://www.nickyee.com/hub/addiction/ addiction.pdf. (accessed December 4, 2017).

29. Zhong Z.-J. The effects of collective MMORPG play on gamers online and offline social capital. Computers in Human Behavior, 2011, no. 6 (27), pp. 2352-2363. 
«Встретимся в дополненной реальности...»: социальные компетенции игроков

\section{Information about the Authors}

Olga V. Sergeeva, Doctor of Sociological Sciences, Associate Professor, Department of Sociology of Culture and Communication, Saint Petersburg State University, Leading Researcher, Sociological Institute of RAS, Universitetskaya Emb., 7-9, 199034 Saint Petersburg, Russian Federation, o.v.sergeeva@spbu.ru.

Anna V. Tsareva, Candidate of Economic Sciences, Associate Professor, Department of Sociology of Culture and Communication, Saint Petersburg State University, Universitetskaya Emb., 7-9, 199034 Saint Petersburg, Russian Federation, a.v.tsareva@spbu.ru.

Nadezhda A. Zinovyeva, Candidate of Sociological Sciences, Associate Researcher, Sociological Institute of RAS, 7-ya Krasnoarmeyskaya St., 25/14, 190005 Saint Petersburg, Russian Federation, n.zinoveva@socinst.ru.

\section{Информация об авторах}

Ольга Вячеславовна Сергеева, доктор социологических наук, доцент кафедры социологии культуры и коммуникации, Санкт-Петербургский государственный университет; ведущий научный сотрудник, Социологический институт ФНИСЦ РАН, Университетская наб., 7-9, 199034 г. Санкт-Петербург, Российская Федерация, o.v.sergeeva@spbu.ru.

Анна Владиславовна Царева, кандидат экономических наук, доцент кафедры социологии культуры и коммуникации, Санкт-Петербургский государственный университет, Университетская наб., 7-9, 199034 г. Санкт-Петербург, Российская Федерация, a.v.tsareva@spbu.ru.

Надежда Андреевна Зиновьева, кандидат социологических наук, ассоциированный научный сотрудник, Социологический институт ФНИСЦ РАН, ул. 7-я Красноармейская, 25/14, 190005 г. Санкт-Петербург, Российская Федерация, n.zinoveva@socinst.ru. 